\title{
Electroless Metallization of Stereolithographic Photocurable Resins for 3D Printing of Functional Microdevices
}

\author{
R. Bernasconi, ${ }^{\mathrm{a}, *}$ C. Credi, ${ }^{\mathrm{b}}$ M. Tironi, ${ }^{\mathrm{a}}$ M. Levi, ${ }^{\mathrm{b}}$ and L. Magagnin ${ }^{\mathrm{a}, \mathrm{z}}$ \\ ${ }^{a}$ Dipartimento di Chimica, Materiali e Ingegneria Chimica "Giulio Natta", Politecnico di Milano, 20131 Milano, Italy \\ ${ }^{b}$ Dipartimento di Chimica, Materiali e Ingegneria Chimica "Giulio Natta", Politecnico di Milano, 20133 Milano, Italy
}

\begin{abstract}
In the present paper the electroless metallization of 3D printed devices using stereolithography is investigated. Two different photocurable resins from a commercial supplier and a self-formulated one are used as starting materials for printing. A first metal layer of $\mathrm{NiP}$ or $\mathrm{Cu}$, obtained by an optimized pretreatment and plating process, is subsequently applied on the parts. The possibility of obtaining multilayers through the successive electrodeposition of different metals on the electroless treated parts is demonstrated as well. From the applicative point of view, the use of 3D printing, coupled with electroless deposition of mono or multilayers, can be employed to manufacture functional microstructures for use in the fields of microrobotics, MEMS, metamaterials and others. For this reason, the realization of a prototypical magnetic actuator is presented as an example of possible application.

(C) The Author(s) 2017. Published by ECS. This is an open access article distributed under the terms of the Creative Commons Attribution 4.0 License (CC BY, http://creativecommons.org/licenses/by/4.0/), which permits unrestricted reuse of the work in any medium, provided the original work is properly cited. [DOI: 10.1149/2.0081705jes] All rights reserved.

(cc) BY
\end{abstract}

Manuscript submitted November 7, 2016; revised manuscript received December 22, 2016. Published January 21, 2017. This was Paper 1102 presented at the San Diego, California, Meeting of the Society, May 29-June 2, 2016. This paper is part of the JES Focus Issue on Biosensors and Micro-Nano Fabricated Electromechanical Systems.

$3 \mathrm{D}$ printing ${ }^{1}$ has recently acquired great relevance for research and industrial applications due to its advantages with respect to traditional manufacturing techniques: the opportunity to create geometries impossible to obtain with other techniques, low cost and great scalability. This technique has been applied in the past for both rapid prototyping and production of custom-made parts. ${ }^{2,3}$ In recent years, thanks to the introduction of techniques able to operate at the microscale, new possibilities have been individuated in fields like microrobotics, MEMS or metamaterials fabrication. Many 3D printing techniques are available, such as stereolithography (SLA), ${ }^{4}$ Selective Laser Sintering (SLS), ${ }^{5}$ Fused Deposition Modelling (FDM) ${ }^{6}$ or Two Photon Lithography (2PL). ${ }^{7}$ Techniques like SLA or 2PL present however significant advantages compared to FDM or SLS when the production of micrometric parts is required. In particular, the products are characterized by an improved surface finish and by the possibility to achieve great resolution; ${ }^{8}$ dimensional tolerances are better than FDM or SLS printing. These important properties allow thinking to applications like the direct printing of microstructures that typically present characteristic dimensions in the order of $\mu \mathrm{m}$, like MEMS or others.

All 3D printing techniques able to operate at the microscale are however characterized by the same problem: metal parts are considerably hard to obtain. The materials used in 3D printing are mainly polymers and only some techniques are suitable for direct metal forming, like SLS. ${ }^{5}$ A possible solution to obtain a metallic finish on a printed object is to metallize only the surface of the resin. This makes possible to obtain some properties of metals without having a bulk metallic object. ${ }^{9}$ In particular it can be convenient to use electroless plating, ${ }^{10}$ a method able to provide thick and uniform metal layers on non-conductive substrates, such as the resins used in the printing step. By examining the existing scientific literature, it is evident that typical polymers used in FDM printing, such as PET, ${ }^{11} \mathrm{ABS},{ }^{12} \mathrm{PLA}$ and PETG $^{13}$ can be easily metallized. A limited amount of information is available in the case of SLA metallization. ${ }^{14}$ In particular pretreatment procedures to promote adhesion in the case of PVD metallization are present, ${ }^{15,16}$ while an optimized method for the metallization of photopolymerizable resins of wide commercial diffusion is not available yet.

The first purpose of this work is therefore to describe a method for electroless plating 3D SLA printed devices, with particular attention

\footnotetext{
*Electrochemical Society Student Member

${ }^{\mathrm{z} E}$-mail: luca.magagnin@polimi.it
}

to the metallization of small parts. Three resins are analyzed to cover in part the wide range of products commercially available as starting materials for SLA printing. The optimized procedure is described and the influence of some parameters on the surface quality of the metal layer is studied. The direct metallization of printed parts takes place through deposition of $\mathrm{Cu}$ and $\mathrm{NiP}$, while the possibility of a subsequent electrodeposition of other metals on top of the first conductive layer is also studied.

Among the possible applications of the electroless deposition method, additive manufacturing of MEMS can be highly attractive. In the case of MEMS, normal silicon based lithography techniques used nowadays are ideal for mass production. On the contrary, when the goal is to manufacture small batches of highly customized devices, the initial investment for starting a classical production can be high. ${ }^{17}$ Flexible and scalable techniques like 3D printing can in this case provide alternative fabrication routes for specialized small productions of MEMS. The possibility of 3D printing functional microdevices has already been demonstrated by some research groups. Garcia et al. for example used SLA to manufacture electrospray devices, ${ }^{18}$ while many works are available on the realization of sensing arrays with different polymers by pattering ${ }^{19,20}$ In this context, application of metallic layers can provide conductivity to the surface of the printed devices or make them sensitive to the presence of magnetic fields. Surface conductivity is in particular crucial if a capacitive readout need to be performed on the devices produced.

The second aim of the present work is thus the application of the $3 \mathrm{D}$ printing/metallization route to realize a simple prototypical magnetic cantilever actuator, following an approach similar to other references present in literature. ${ }^{21,22}$ Similar structures, obtained via a fully electroless fabrication method, have already been described in a previous work. ${ }^{23}$ The present investigation is on the contrary focused on the production of magnetically active cantilevers using a hybrid electroless/electrolytic process and on their possible use as actuator prototypes. The qualitative analysis of their behavior is useful to give a perspective to the work presented and to open the way to the future development of MEMS devices produced with the hybrid 3D printing/wet metallization method.

\section{Experimental}

Characterization of electroless deposition on photocurable resins.-The samples used for the characterization of the process have been printed using a Digital Wax 028J PLUS 3D SLA printer by 
DWS and subjected to post-baking with UV light after printing. Two commercial light-curable resins were used: DL260 and Irix White, both produced by DWS. The former is characterized by an elastic modulus of $1820 \mathrm{MPa}$, while the latter reaches a value of $2610 \mathrm{MPa}$. The exact formulation of the two resins is proprietary, nevertheless they are in general acrylate-urethane based materials. The third material employed is a self-formulated resin obtained using SR349 (by Sartomer) as monomer and TPO-L (by BASF) as photoinitiator. This material present values of elastic modulus around $2500 \mathrm{MPa}$. The samples measured $1 \mathrm{~cm} \times 1 \mathrm{~cm}$ with a square shape $(1 \mathrm{~mm}$ thickness). All chemicals used in the metallization phase were purchased from Sigma-Aldrich and used without further purification. The first part of the metallization process consisted of a neutral degreasing with a solution having the following composition: $50 \mathrm{~g} / \mathrm{l}$ of sodium carbonate, $35 \mathrm{~g} / \mathrm{l}$ of disodium metasilicate and $3 \mathrm{~g} / \mathrm{l}$ of sodium lauryl sulfate. The treatment was carried out at room temperature for 2 minutes under sonication. The samples were then washed with deionized water. After degreasing, the samples were immersed in a solution of $200 \mathrm{~g} / \mathrm{l} \mathrm{KOH}$ at $45^{\circ} \mathrm{C}$ for 30 minutes and then washed with deionized water. The activation for the electroless plating was carried out dipping the samples in an industrial palladium based activator (Neoganth 834 by Atotech $\mathrm{GmbH}$ ) for 10 minutes at room temperature and subsequently in a reducing solution of $20 \mathrm{~g} / \mathrm{l}$ sodium borohydride for 30 seconds at room temperature. These two steps have been performed two times and the samples were not washed between immersion in the activator and in the reducing agent. Once activated, the samples were immersed in the solutions for the deposition of $\mathrm{NiP}$ and $\mathrm{Cu}$. In particular, NiP with a $\mathrm{P}$ content of $2-3 \%$ wt was deposited from an alkaline solution containing $32 \mathrm{~g} / \mathrm{l}$ of nickel sulfate hexahydrate, 20 $\mathrm{g} / \mathrm{l}$ of trisodium citrate, $25 \mathrm{~g} / \mathrm{l}$ of ammonium chloride and $28 \mathrm{~g} / \mathrm{l}$ of sodium hypophosphite. ${ }^{24}$ The $\mathrm{pH}$ has been adjusted to 9 using ammonium hydroxide and the deposition was performed under vigorous stirring at $45^{\circ} \mathrm{C}$. In the case of $\mathrm{Cu}$, a solution containing $20 \mathrm{~g} / \mathrm{l}$ of copper sulfate pentahydrate, $40 \mathrm{~g} / \mathrm{l}$ of disodium EDTA, $10.5 \mathrm{~g} / \mathrm{l}$ of glyoxylic acid, $10 \mathrm{mg} / \mathrm{l}$ of 2,2'-bipyridine and $10 \mathrm{mg} / \mathrm{l}$ of potassium ferrocyanide was employed. The $\mathrm{pH}$ was corrected to 12 with sodium hydroxide and the solution was used at $45^{\circ} \mathrm{C}^{25}$ with stirring. SEM and EDS analysis were performed using a EVO 50 EP microscope by Zeiss. Adhesion between the polymer and the metal was estimated by means of a peel test. The DSC analysis was performed with a STARe SW 9:30 instrument. The thickness of the obtained layers was measured with a XRF X-RAY XAN apparatus by Fischerscope, while surface rugosity was evaluated with a laser profilometer UBM Microfocus. Contact angle was measured using a microcamera to acquire the shape of water droplets dispensed by a needle on the surface of

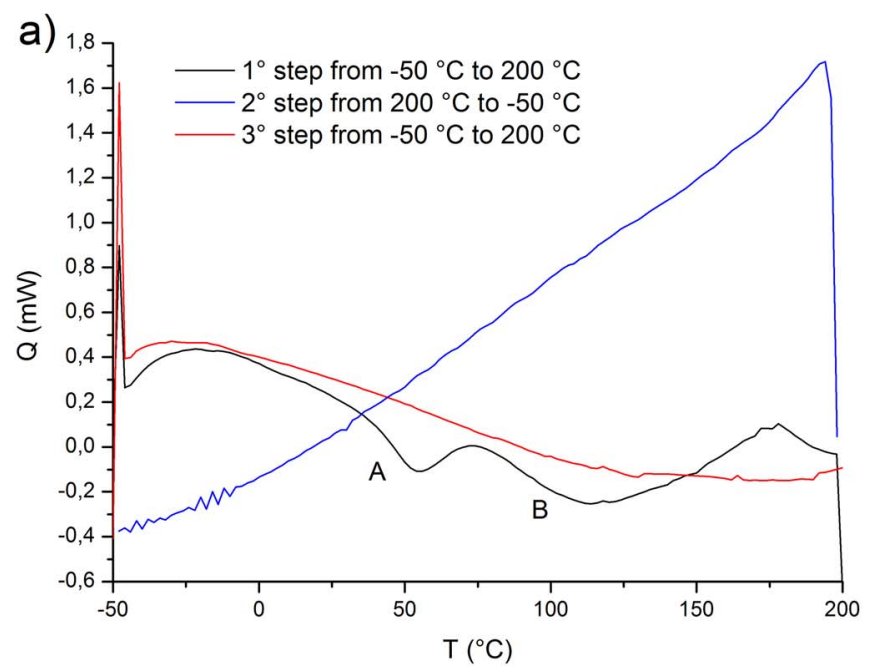

the samples. Acquired drop profile was analyzed by mean of the Drop Shape Analysis software. Optical microscopy was performed using a Leica DM LM microscope.

Manufacturing of prototypical magnetic actuators.-Cantilevers having the following dimensions were SLA printed using DL260: 9 $\mathrm{mm}$ length, $0.6 \mathrm{~mm}$ width and $0.2 \mathrm{~mm}$ thickness. The cantilevers were printed connected to a base having the following dimensions: $10 \mathrm{~mm}$ length, $10 \mathrm{~mm}$ width and $5 \mathrm{~mm}$ thickness. The cantilevers were metallized with the $\mathrm{Cu}$ electroless bath described previously to provide a first conductive layer. Subsequently, $3 \mathrm{~mm}$ of the cantilever (starting from the tip) were dipped in two electrolytic bath and connected as cathodes to perform electrodeposition. The first bath was designed to deposit permalloy and was composed of the following chemicals: $14 \mathrm{~g} / \mathrm{l}$ iron sulfate heptahydrate, $200 \mathrm{~g} / \mathrm{l}$ nickel sulfate heptahydrate, $20 \mathrm{~g} / \mathrm{l}$ trisodium citrate, $25 \mathrm{~g} / \mathrm{l}$ sodium chloride, $40 \mathrm{~g} / \mathrm{l}$ boric acid, $3 \mathrm{~g} / \mathrm{l}$ saccharine and $0.3 \mathrm{~g} / \mathrm{l}$ sodium lauryl sulfate. The second bath was designed to deposit pure Co and was composed of the following chemicals: $30 \mathrm{~g} / \mathrm{l}$ cobalt sulfate heptahydrate, $5 \mathrm{~g} / \mathrm{l}$ cobalt chloride hexahydrate, $8 \mathrm{~g} / \mathrm{l}$ boric acid and $0.4 \mathrm{~g} / \mathrm{l}$ saccharine. Deposition of permalloy was performed for $60 \mathrm{~min}$ at $10 \mathrm{~mA} / \mathrm{cm}^{2}, 30^{\circ} \mathrm{C}$ and $\mathrm{pH} 3.5$. Pure Co plating was done at $30 \mathrm{~mA} / \mathrm{cm}^{2}, \mathrm{pH} 3$ and room temperature for $30 \mathrm{~min}$. Actuation of the cantilevers was achieved using a setup already employed in literature: ${ }^{23}$ a magnet was collocated at different distances from the cantilever and the deflection at the tip was measured with a video acquisition system. A sintered $\mathrm{NdFeB}$ magnet of grade N45 was employed, having the following dimensions: $2 \mathrm{~cm}$ as diameter and $1 \mathrm{~cm}$ as thickness.

\section{Results and Discussion}

The characterization of the deposition process was performed using samples of dimensions $1 \mathrm{~cm} \times 1 \mathrm{~cm}$. For their fabrication, default parameters of the stereolithographic printer were used.

Characterization of the resins.-Two of the resins used are commercial products. For this reason, the exact chemical composition is unknown. However, some properties of the materials are interesting for the planning of the electroless metallization process and, for this reason, some preliminary analysis was carried out on the cured resins. The first characterization performed was the differential scanning calorimetry (DSC). Figure 1a represents the DSC curve for DL260 resin between $-50^{\circ} \mathrm{C}$ and $200^{\circ} \mathrm{C}$. Two increasing temperature scans and one decreasing temperature scan have been performed.

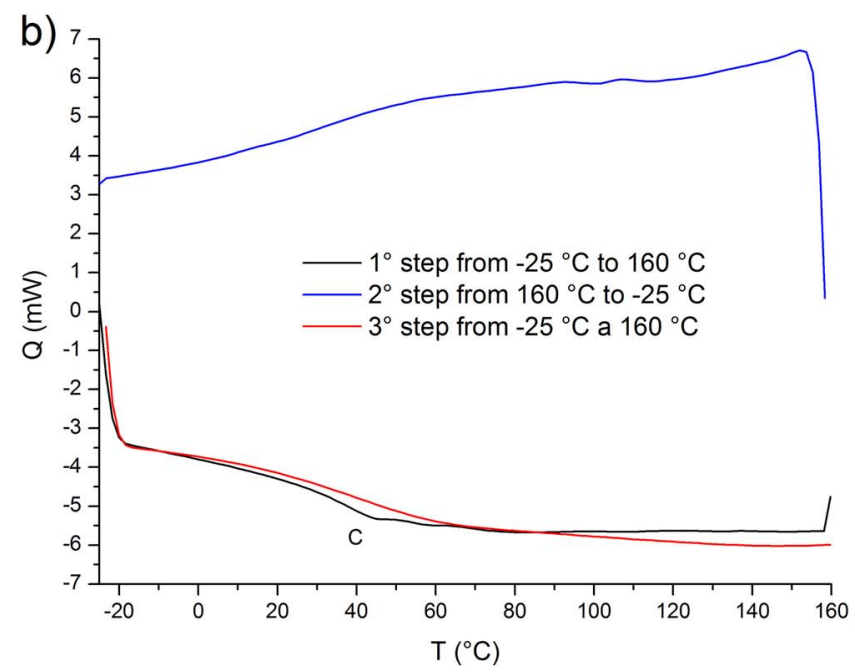

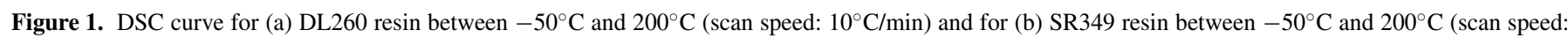
$\left.10^{\circ} \mathrm{C} / \mathrm{min}\right)$. 

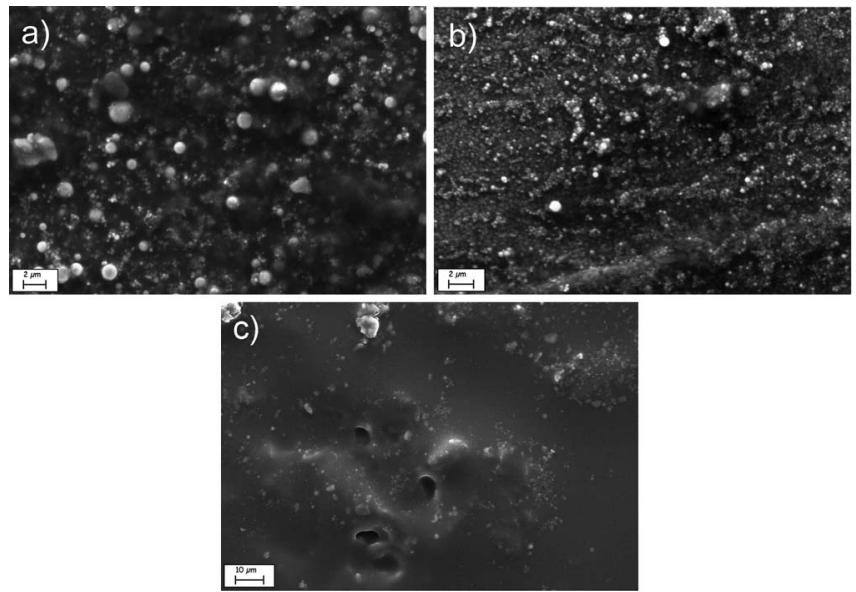

Figure 2. SEM image of a (a) DL260 resin sample (10000 X magnification), of a (b) Irix White resin sample (14000 X magnification) and of a (c) SR349 resin sample (2500 X magnification).

It is evident the presence of a glass transition (point A in Figure 1a) between $45^{\circ} \mathrm{C}$ and $50^{\circ} \mathrm{C}$, followed by a second transformation after $80^{\circ} \mathrm{C}$ (point $\mathrm{B}$ in Figure 1a). Once brought to $200^{\circ} \mathrm{C}$ and subsequently cooled again to $-50^{\circ} \mathrm{C}$, the resin no longer shows the same behavior if heated up again to $200^{\circ} \mathrm{C}$. Irreversible changes hence occur in the material upon exposure to high temperatures. It is however the first transformation (point $\mathrm{A}$ in Figure 1a) that limits the metallization process, which will necessarily occur at equal or lower temperatures to ensure the dimensional stability of printed parts. In the case of higher metallization temperatures, local deformations were observed in the case of small or thin particulars in 3D printed samples. Even in the case of Irix White resin, whose DSC graph obtained at $10^{\circ} \mathrm{C} / \mathrm{min}$ is similar, it is possible to observe two major transitions. The glass transition takes place at about $50^{\circ} \mathrm{C}$, while the second transformation takes place over $90^{\circ} \mathrm{C}$. The resin behavior is similar to the DL260 resin also in the case of a second heating cycle. In fact, during the third step, transitions similar to the ones detected in the first step are no longer observed. Figure $1 \mathrm{~b}$ reports the behavior of the SR349 resin when subjected to the same thermal cycle. SR349 presents only one transition (point $\mathrm{C}$ in Figure 1b) around 40 and $45^{\circ} \mathrm{C}$, and also in this case no transitions are observed during the second scan from $-50^{\circ} \mathrm{C}$ to $200^{\circ} \mathrm{C}$. Considering the data obtained by the SDC of the three resins, an operating temperature of $45^{\circ} \mathrm{C}$ was selected for the electroless solutions. Suitable solutions, able to operate at low temperature, were therefore selected from the existing literature. Then the resins were analyzed by SEM to evaluate surface morphology. The reported SEM microphotographs (Figure 2) also exemplify the reason for the choice of the three materials used, since DL260 and Irix White are two resins loaded with different amounts of silica microparticles while SR349 is free of particles. These materials constitute good examples of typical resins of common use in SLA. Figure 2a shows the micrograph obtained in the case of DL260 resin.

The spheroidal particles visible in Figure $2 \mathrm{a}$ are constituted of $\mathrm{SiO}_{2}$ (silica), which is used as filler by the resin manufacturer to change its mechanical properties. A subsequent thermogravimetric analysis allowed to establish that such particles make up about $20 \%$ wt. of the resin. Figure $2 b$ represents the Irix White resin observed by SEM under similar conditions. Even the Irix White resin appears loaded with silica but, if compared to DL260, its particles appear finer and more concentrated. A thermogravimetric analysis allowed to fix the silica content at $40 \%$ wt. Figure 2c shows the morphology of the SR349 resin. Due to the lack of a reinforcement, SR349 appears considerably flat and uniform when observed with SEM. Measured average surface roughness $\left(\mathrm{R}_{\mathrm{a}}\right)$ values are equal to $0.208 \mu \mathrm{m}$ for DL260, $0.156 \mu \mathrm{m}$ for Irix White resin and $0.083 \mu \mathrm{m}$ for SR349. These values were measured on the flat upper side of the planar $1 \mathrm{~cm} \times 1 \mathrm{~cm}$
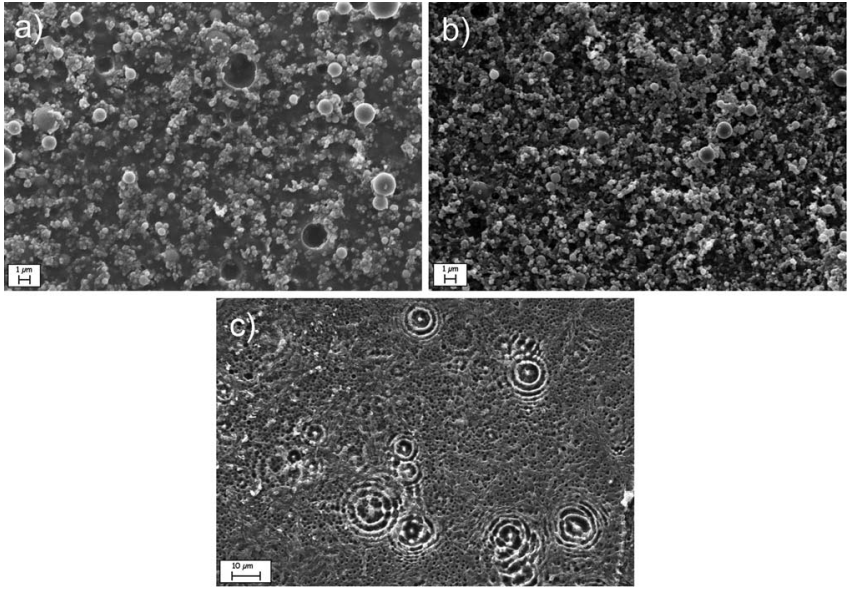

Figure 3. SEM image for the resins samples treated for 10 minutes in $\mathrm{KOH}$; DL260 at $10000 \mathrm{X}$ magnification (a), Irix White at $10000 \mathrm{X}$ magnification (b), SR349 at $2500 \mathrm{X}$ magnification (c).

samples used for the characterization. According to the direction of SLA printing, surface roughness can however vary significantly as a result of the pattern followed by the laser to solidify the resin.

Pretreatment for electroless metallization.-Immediately after the preliminary degreasing step, printed samples were immersed in an etching solution of $\mathrm{KOH}$ in temperature $\left(45^{\circ} \mathrm{C}\right)$, in order to roughen the surface of the samples to favor a better adhesion of the metal. Besides morphological modification, the process has a side effect on the chemical properties of the surface, which in general becomes more hydrophilic and compatible with the aqueous solutions used in the process. Figure 3 shows the effect on the surface morphology after the immersion in the alkaline etching solution for 10 minutes.

The treatment was stopped a first time after $10 \mathrm{~min}$ in the case of SEM observation to better observe the morphologies obtained. The highly alkaline solution partly removed the polymer between the silica particles, which are visibly more exposed (Figures $3 \mathrm{a}$ and $3 \mathrm{~b}$ ) than in the untreated resin (Figures $2 \mathrm{a}$ and $2 \mathrm{~b}$ ). Therefore, $\mathrm{KOH}$ treated resins present a greatly roughened surface, capable of providing good adhesion between the sample and the coating. In the case of SR349 (Figure 3c) the aggressive action of $\mathrm{KOH}$ eroded the surface of the resin as well, but it created circular patterns in some regions. Such patterns can probably be correlated with the presence of some degree of crystallinity in the material. Local variation in crystallinity can in fact induce preferential ways for alkaline corrosion, creating thus regular patterns on the surface. These appears as concentric rings having an apparently random distribution. Such ring patterns cannot be due to incomplete polymerization, because the resin is post-cured after the printing. The structures observed are however not present on the entire surface of the samples. This fact can be a consequence of a not uniform polymerization operated by the laser during printing, which induces a different local behavior of the resin in presence of $\mathrm{KOH}$. The increase of etching time from $10 \mathrm{~min}$ to $30 \mathrm{~min}$ does not alter the general morphology observed in Figure 3. The typical morphological features are however slightly amplified and the roughness increases with respect to the 10 min etching case (as visible in Figure 4a, except for Irix White). The effect on adhesion is nevertheless notable, with better adhesion obtained in the case of $30 \mathrm{~min}$ immersion time.

Figure 4 reports the values of roughness and contact angle measured after 10 minutes and 30 minutes of treatment.

As evident in Figure 4a, roughness in general increased with increasing immersion times in $\mathrm{KOH}$. In the case of Irix White a slight decrease in roughness was observed as a consequence of a probable removal of particles from the surface. At low etching times, only the resin between the particles is removed, but at high treatment times, since in this resin particles concentration is high (around 40\%), 

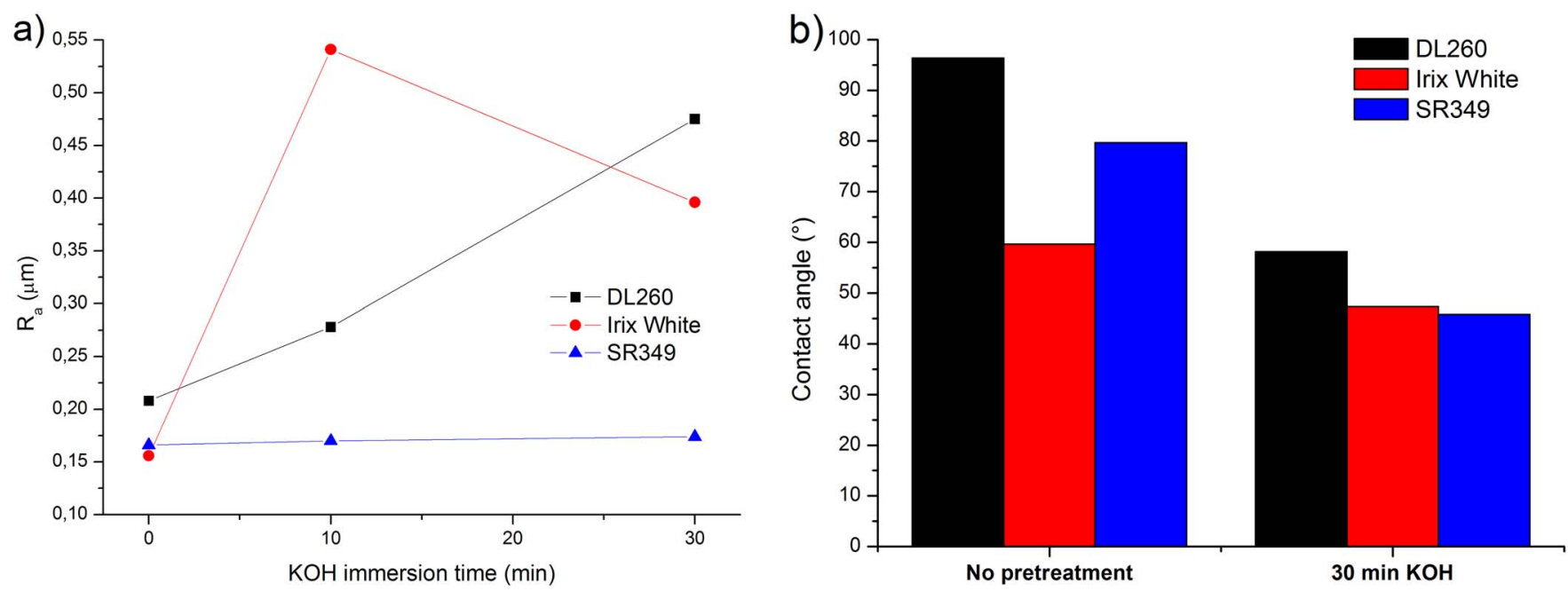

Figure 4. Roughness (a) and contact angle (b) evolution for the different resins as a function of immersion time in $\mathrm{KOH}$.

particles are actively detached from the surface. The result is a decrease in roughness. A decrease in contact angle (Figure $4 \mathrm{~b}$ ) was observed for all the resins. The reason for this behavior must be searched in the chemical structure of the photocurable polymers. The exact chemistry of the two proprietary resins is not known, but it is typically characterized by the presence of acrylate and urethane monomers mixtures and a photoinitiator. In the case of SR349, the monomer is an acrylate as well. Acrylate monomers are characterized by the presence of an ester bond -CO-O-. Ester bonds are known to present a significant reactivity in alkaline environment, as already demonstrated in existing literature. ${ }^{26,13}$ The general degradation mechanism is represented by Equation 1.

$$
\mathrm{R}_{1}-\mathrm{CO}-\mathrm{O}-\mathrm{R}_{2}+\mathrm{OH}^{-} \rightarrow \mathrm{R}_{1}-\mathrm{CO}-\mathrm{OH}+\mathrm{HO}-\mathrm{R}_{2}
$$

The first effect of this reaction is the dissolution of the resin upon exposure to an alkaline environment. This easily explains the increase in roughness observed in Figure 4a. The second effect obtained from the degradation reaction is the introduction of new functional groups on the surface. Such groups, namely $-\mathrm{COOH}$ and $-\mathrm{OH}$, are characterized by a polar nature. For this reason surface energy change and contact angle decreases. SR349 looks less reactive than the two commercial resins. Both contact angle decrease and roughness increase are beneficial for the subsequent electroless step. A high roughness

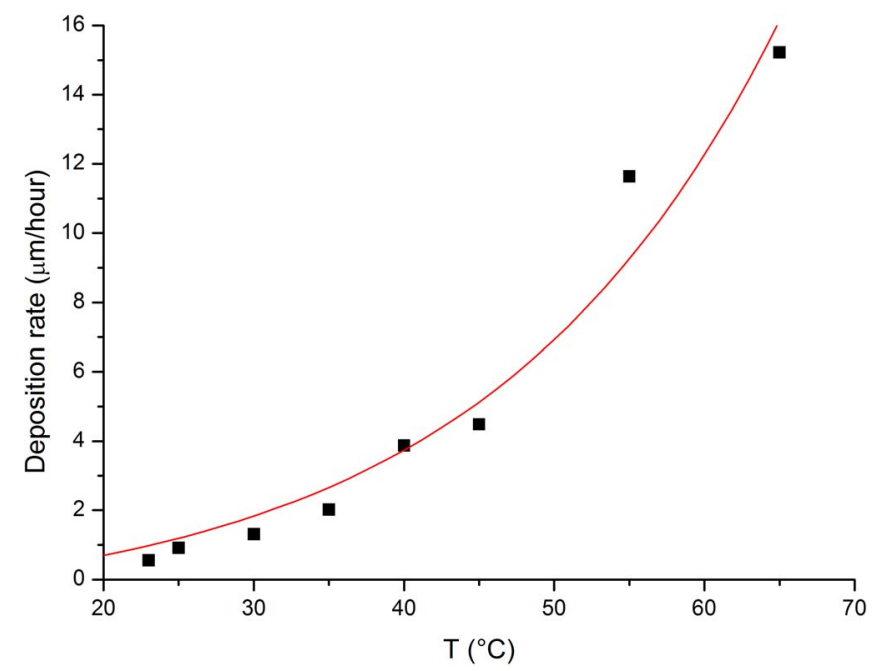

Figure 5. The effect of bath temperature on the deposition rate of NiP. improves adhesion of the metallic layer, while a low contact angle results beneficial for the activation of the surface. $\mathrm{Pd}^{2+}$ adsorption from the Neoganth 834 activator is strongly dependent on surface wettability. Low contact angles increase the quantity of adsorbed metal as well as its uniformity on the surface. $\mathrm{Pd}^{2+}$ is subsequently reduced to metallic Pd by the immersion in the sodium boron hydride solution. Untreated samples showed insufficient adhesion during peel tests.

NiP metallization.-After etching and activation steps, the samples were immersed in the solution for the deposition of NiP. The graph in Figure 5 shows the relationship between temperature and deposition rate in the case of the solution used. The bath considered, due to its alkaline $\mathrm{pH}$ corrected with ammonium hydroxide, is suitable for low temperature operation (in contrast with the common industrial $\mathrm{NiP}$ solutions at acidic $\mathrm{pH}$ ). However, it is evident that, at the chosen operating temperature $\left(45^{\circ} \mathrm{C}\right)$, the deposition rate of the metal layer is low: $4.4 \mu \mathrm{m} / \mathrm{h}$.

Figure 6 shows the surface morphology of DL260 resin after the deposition of about $1.5 \mu \mathrm{m}$ of $\mathrm{NiP}$ (20 minutes of immersion in NiP solution). A uniform layer of metal alloy characterized by a good surface finish covers the sample.

Adhesion to the substrate, verified by peel test, was good with a treatment time of $30 \mathrm{~min}$ in $\mathrm{KOH}$. If $10 \mathrm{~min}$ of etching time was used, adhesion was found to be inferior and the coverage of the metal layer was not uniform. These two effects can be a consequence of a too low roughness level (Figure 4a) and of a contact angle too high

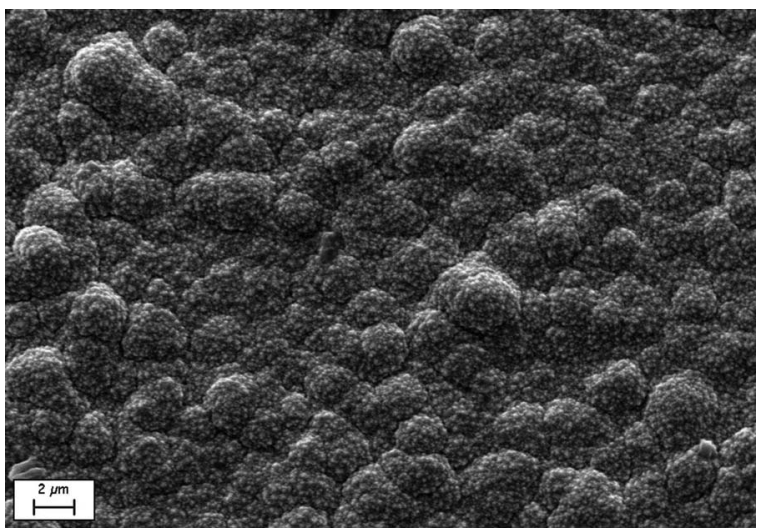

Figure 6. SEM image of a DL260 resin sample plated with NiP (10000 X magnification). 


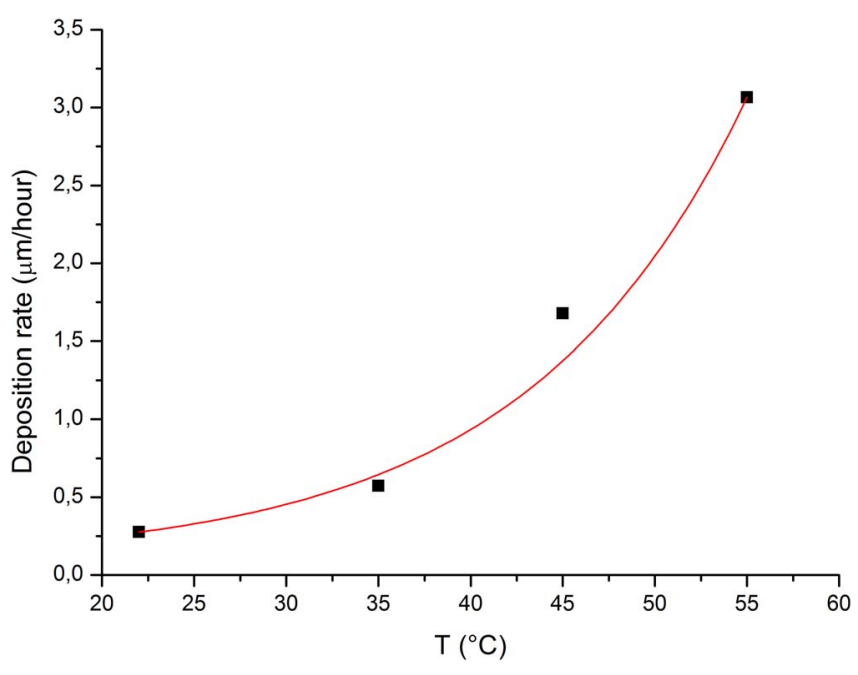

Figure 7. The effect of bath temperature on the deposition rate of $\mathrm{Cu}$.

(Figure 4b). Initial roughness after 30 min etching was $0.464 \mu \mathrm{m}$ for the DL260 resin, $0.412 \mu \mathrm{m}$ for Irix White resin and $0.182 \mu \mathrm{m}$ in the case of SR349.

The result obtained with the same operating conditions in the cases of the resin Irix White and SR349 are not reported because of their almost total equivalence to the case of DL260 resin. No evident differences in surface morphology can be observed, but the three samples covered by NiP present slightly different roughness values. The average surface roughness is equal to $0.282 \mu \mathrm{m}$ for the DL260 resin, to $0.387 \mu \mathrm{m}$ for Irix White resin and to $0.289 \mu \mathrm{m}$ in the case of SR349.

Cu metallization.-The pretreatment process described for the $\mathrm{NiP}$ metallization was applied also in the case of $\mathrm{Cu}$ metallization. Figure 7 shows the trend of the deposition rate as a function of temperature in the case of the solution used. Copper is present in the bath as EDTA complex, therefore the overall stability of the solution is good. However, this stability lowers the deposition rate. The need to use a temperature of $45^{\circ} \mathrm{C}$ amplifies the decrease in the deposition rate, that reaches values lower than $2 \mu \mathrm{m} / \mathrm{h}$.

Figure 8a shows the surface morphology resulting from the metallization of a sample of Irix White resin. The copper layer was deposited through 1 hour of immersion in the solution and measured about 2 $\mu \mathrm{m}$ in thickness. Also in this case the adhesion to the substrate and the uniformity of the coating were found to be good, and also in this case a pretreatment time of $30 \mathrm{~min}$ was employed.

Surface finish looks better than for NiP. As for the metallization with $\mathrm{NiP}$, the case related to $\mathrm{Cu}$ plated DL260 resin is not reported for its substantial equivalence with results visible in Figure 8a. This is not true for SR349, whose surface morphology is visible in Figure 8b. The surface of the sample appears to be more uniform with respect to the case shown in Figure 8a. This can be a consequence of a minor levelling power of the $\mathrm{Cu}$ electroless deposition bath with respect to
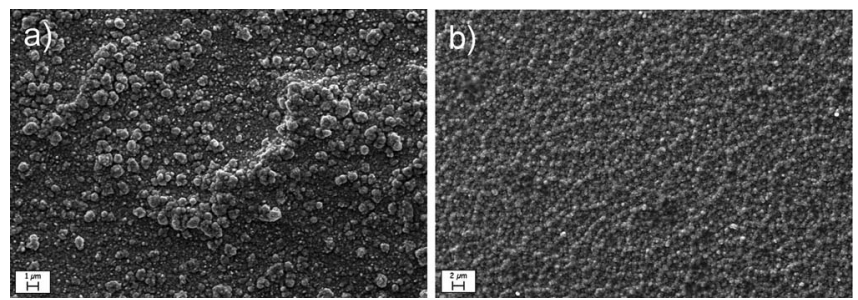

Figure 8. SEM image of a Irix White resin sample (a) plated with $\mathrm{Cu}$ (10000 X magnification) and of a Cu plated SR349 (b) sample (5000 X magnification).
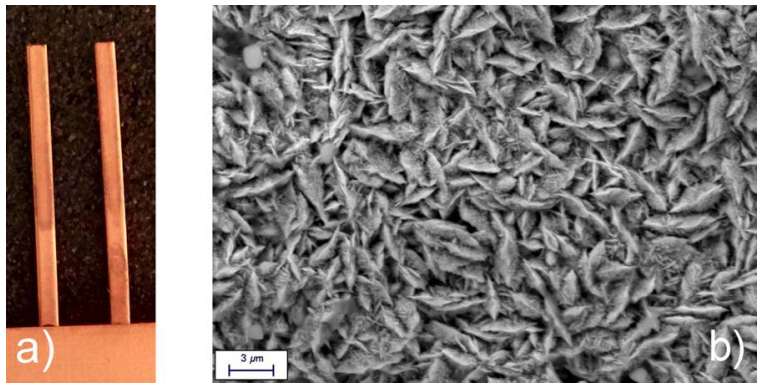

Figure 9. Visual appearance of two $\mathrm{Cu}$ coated cantilevers (a) and SEM microphotography of the Co as plated (b) surface (10000 X magnification).

the $\mathrm{NiP}$ one. In that case, a similar morphology was observed for all the samples. In the case of $\mathrm{Cu}$, on the contrary, final morphology is more dependent on the initial one of the substrate. The average surface roughness is equal to $0.247 \mu \mathrm{m}$ for the DL260 resin and to 0.263 $\mu \mathrm{m}$ for the Irix White resin, while SR349 presents a value of $R_{a}$ of $0.186 \mu \mathrm{m}$.

Once the first electroless layer is applied, the surface becomes conductive and electrodeposited layers can be applied on top. ${ }^{27}$ The metallic layer deposited on the surface of the polymer can also be used as base coating for deposition of other electroless layers. This is motivated by the fact that some metals or alloys grow in a better way on another metal than on the activated resin. The possibility to apply electroless layer on the first base coating has been demonstrated in a previous work. ${ }^{23}$ In the present treatise, the application of electrodeposited layers is on the contrary investigated. Pure Co and permalloy (containing $18.78 \% \mathrm{Fe}$ according to EDS) were electrolytically plated on a first electroless $\mathrm{Cu}$ layer.

Metallization of $3 D$ printed microstructures: magnetic actuators.-The metallization process described previously is general and can be applied for decorative purposes as well as functional applications. As anticipated in the introduction, an attractive possible application is the realization of microdevices in the field of MEMS. To give a perspective on this topic, prototypical magnetic actuators were built in the present work. Both direct metallization of the photocurable resin and the deposition of multilayers find application during their manufacturing process. Figure 9a shows the external appearance of the cantilevers after the application of a first $\mathrm{Cu}$ layer at $45^{\circ} \mathrm{C}$ for 20 minutes.

After the first electroless step, the $\mathrm{Cu}$ coated cantilever arrays were immersed in the two electrolytic baths for $3 \mathrm{~mm}$ starting from the tip to apply the magnetic alloys. A $13.7 \mu \mathrm{m}$ thick permalloy layer and a $5.8 \mu \mathrm{m}$ thick Co layer were obtained. Figure 9b reports the SEM analysis performed on the surface of a cantilever coated with Co. Figure 10 represents a section of a permalloy coated cantilever tip. It is evident that the real section of the cantilever does not correspond to the nominal one. A significant radius of curvature in fact characterizes the corners

Two soft magnetic alloys, $\mathrm{Co}$ and $\mathrm{NiFe}$, were selected as magnetic materials due to the lack of permanent magnetization. If the material is characterized by high remanence and coercivity, the resulting magnetization can interfere with the behavior of the cantilever. The use of materials that magnetize only in presence of an external magnetic field is therefore preferable. NiFe and $\mathrm{Co}$ are both soft magnetic alloys but characterized by different mechanical and magnetic properties. They were used to investigate the difference in behavior between two materials applied on the same cantilevers.

A cantilever for each alloy was selected in the array and placed under a $\mathrm{NdFeB}$ magnet, using a setup analogous to the one already described in a previous work. ${ }^{23}$ The axis of the magnet was placed in correspondence of the part of the cantilever covered by the magnetic material. It was therefore collocated at half the length of the metallized part $(3 \mathrm{~mm} / 2=1.5 \mathrm{~mm}$ from the tip). Under the influence of 


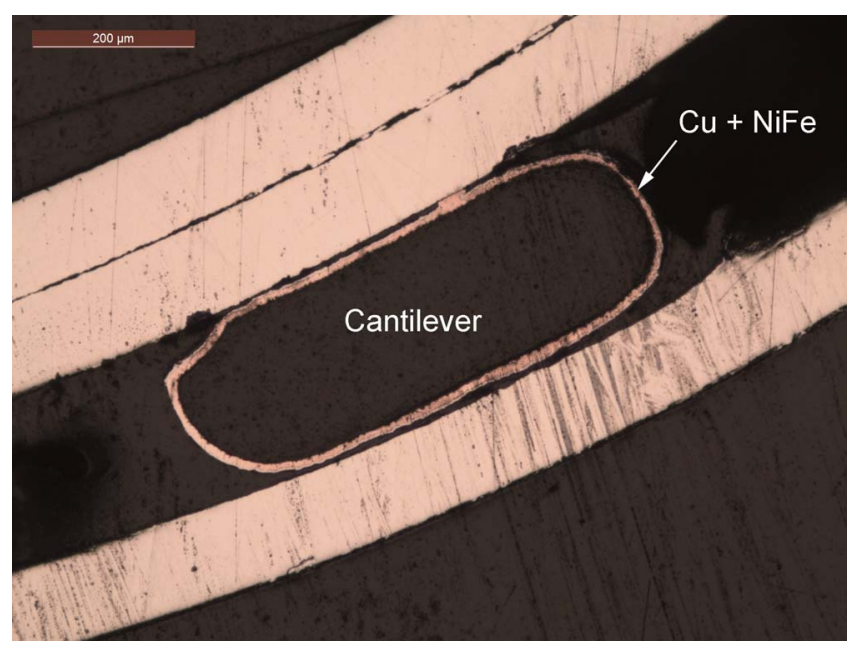

Figure 10. Section of a NiFe plated cantilever.

the magnetic field produced by the magnet, the tip of the cantilever deflected from its rest position. The distance from the cantilever tip was varied and the resulting variation in displacement of the tip was measured. Figure 11a represents the result obtained for the two cantilevers, coated with $\mathrm{Co}$ and $\mathrm{NiFe}$.

A more convenient representation of the data depicted in Figure 11a can be obtained if the magnetic field applied on the tip is considered instead of the distance of the magnet. Such distance can be correlated with the magnetic field experienced by the sample by using an approximate expression ${ }^{28}$ like Equation 2.

$$
H=\frac{\mu_{0} M_{r}}{2}\left(\frac{D+z}{\sqrt{R^{2}}+(D+z)^{2}}-\frac{z}{\sqrt{R^{2}+z^{2}}}\right)
$$

$\mathrm{M}_{\mathrm{r}}$ represents the residual magnetization of the permanent magnet, $\mathrm{D}$ is the thickness of the magnet, $\mathrm{R}$ is the radius of the magnet and $\mathrm{z}$ is the distance from the face of the magnet itself. Some approximations must be considered when applying the equation presented. The calculation is valid only on the axis of the magnet. The dimension of the plated zone at the end of the cantilever is however large with respect to the dimension of the magnet. For this reason only a small region, the one placed exactly on the axis of the magnet, experiences the calculated magnetic field. Vertical deflection of the two samples as a function of the imposed magnetic field $\mathrm{H}$ is reported in Figure 11b. By considering only Figure $11 \mathrm{~b}$, the correlation between the applied magnetic field and the displacement of the tip looks roughly linear. Since the force exerted by the magnet is not concentrated on the tip but it's applied on an area of the cantilever, the normal expression used to calculate the deflexion of a beam loaded at the extremity cannot be used. Deflection of the tip depends, for small displacements, on Equation 3. ${ }^{29}$

$$
\delta=\frac{F b^{2}}{6 E^{*} I}(3 l-b)
$$

$\mathrm{F}$ is the load (e.g. the force exerted by the magnet), 1 is the length of the sample, $\mathrm{E}$ is the elastic modulus of the material and $\mathrm{I}$ is the inertia momentum of the cantilever and $b$ is the distance between the point where the load is applied and the base of the cantilever. It is immediately evident that a first reason for the different behavior of the two cantilevers is the difference in elastic modulus of the two alloys. Moreover, the permalloy coated sample presents a thicker coating with respect to the Co coated one, resulting in a different momentum of inertia of the section. The difference in elastic modulus determines two different equivalent elastic moduli $\mathrm{E}^{*}$ for the composite resin/coating structure. Equivalent elastic modulus is the result of the coupling between $E_{\text {pol }}$ of the cantilever (that is made of resin) and $E_{\text {met }}$ of the metallic layer. If $E_{\text {met }}$ decreases, deflection of the cantilever increases. $\mathrm{E}^{*}$ can be estimated using Equation $4 .^{30}$

$$
E^{*}=\frac{E_{\text {res }} I_{\text {res }}+E_{\text {coat }} I_{\text {coat }}}{I_{\text {tot }}}
$$

$\mathrm{E}_{\text {res }}$ and $\mathrm{E}_{\text {coat }}$ represent the elastic modulus of the resin and of the coating respectively, $\mathrm{I}_{\text {res }}$ and $\mathrm{I}_{\text {coat }}$ are the momentum of inertia for the sections made of resin and of metal. $\mathrm{I}_{\mathrm{tot}}$ is the momentum of inertia for the complete section, including both resin and coating. As visible from the equation, deflection is also directly depending on the force applied on the cantilever. Such force is described by Equation 5 .

$$
F=\mu V|M \nabla \mathrm{H}|
$$

$\mathrm{V}$ represents the volume of the active material, $\mu_{0}$ is the magnetic permeability of vacuum, $\mathrm{M}$ is the magnetization of the material and $\mathrm{H}$ is the magnetic field applied. By considering Equation 5, it is evident that a second factor influencing the deflection of the cantilever is the thickness of the coating (and consequently the volume of the active material). In the case of permalloy, it is higher than the Co plated sample. Finally, the third property that can determine the maximum deflexion of the cantilever is magnetization. $\mathrm{NiFe}$ and Co present two different hysteresis behaviors and saturation magnetization values.
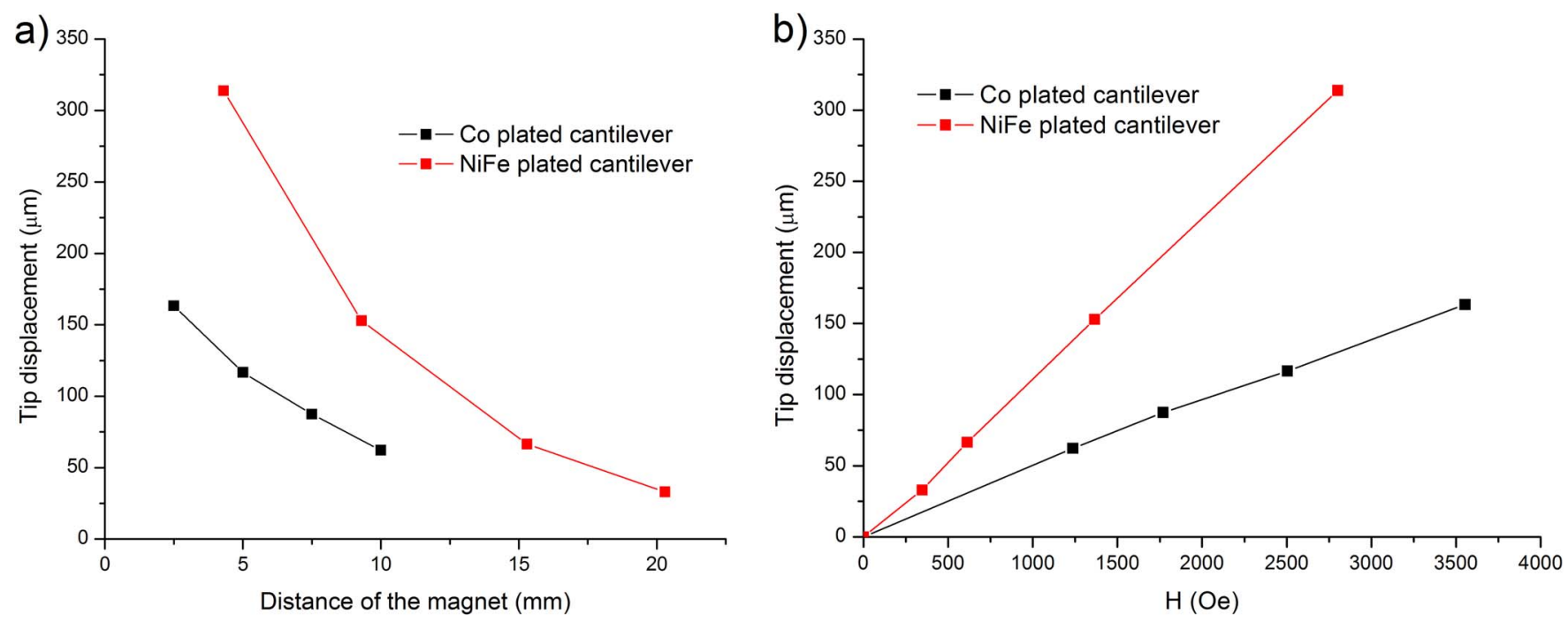

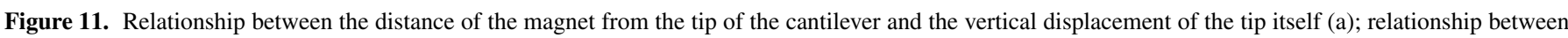
the applied $\mathrm{H}$ field and the displacement of the cantilever (b). 
Table I. Variables used to calculate theoretical displacement of the permalloy coated cantilever.

\begin{tabular}{lll} 
Variable & Value & Reference \\
\hline $\mathrm{M}_{\mathrm{r}}$ of the magnet & $1.32 \mathrm{~T}$ & 31 \\
$\mathrm{M}_{\mathrm{s}}$ for permalloy & $0.86 \mathrm{~T}$ & 32 \\
$\mathrm{E}_{\text {res }}(\mathrm{DL} 260)$ & $1.82 \mathrm{GPa}$ & 33 \\
$\mathrm{E}_{\text {coat }}($ electrodeposited $\mathrm{Cu})$ & $110 \mathrm{GPa}$ & 34
\end{tabular}

Permalloy is a desirable material for MEMS applications because it reaches magnetic saturation almost immediately and this property can be thus considered constant and independent from the applied field. This approach is commonly used in literature to simplify modellization of devices. ${ }^{21}$

An exact estimation of the displacement in the case of the two materials is difficult and outside the scope of the paper. An approximate solution is however useful to evaluate if the order of magnitude of the displacement is realistic and if the relationship showed in Figure 11b can be linear according to the equations considered. For this reason realistic values for unknown variables were considered according to Table I. Calculation was performed only in the case of the permalloy coated sample because this material, as already said, reaches almost instantaneously its saturation magnetization $\mathrm{M}_{\mathrm{s}}$. For this reason, this variable can be considered constant and not subject to hysteresis. By looking at Figure $11 \mathrm{~b}$, it is probable that this property is true also in the case of electroplated Co. Plated Co can present values of $M_{s}$ significantly different according to the electrolyte used, to deposition parameters and to the presence of fcc or hcp phases. The Co samples is thus presented only as comparative example with respect to the permalloy one.

$\mathrm{Cu}$ is considered as $\mathrm{E}_{\mathrm{coat}}$ for the analysis because only the tip of the cantilever is coated with permalloy, while the remaining part is coated with the electroless $\mathrm{Cu}$. For this reason, being the NiFe coated zone far from the base of the cantilever, only $\mathrm{Cu}$ was considered for the calculation of equivalent $E^{*}$. Figure 12 a reports the force acting on the tip of the cantilever calculated using Equations 5 and 2, while Figure $12 \mathrm{~b}$ represents the theoretical displacement of the tip calculated using the previous result and Equations 3 and 4.

As visible in Figure $12 \mathrm{~b}$, calculated data underestimate experimental data. This is due to the existence of many deviations from the ideal theory considered that are difficult to implement in a more sophisticated model. Some of them are:

- Equation 4 for the estimation of composite modulus $\mathrm{E}^{*}$ is an approximation

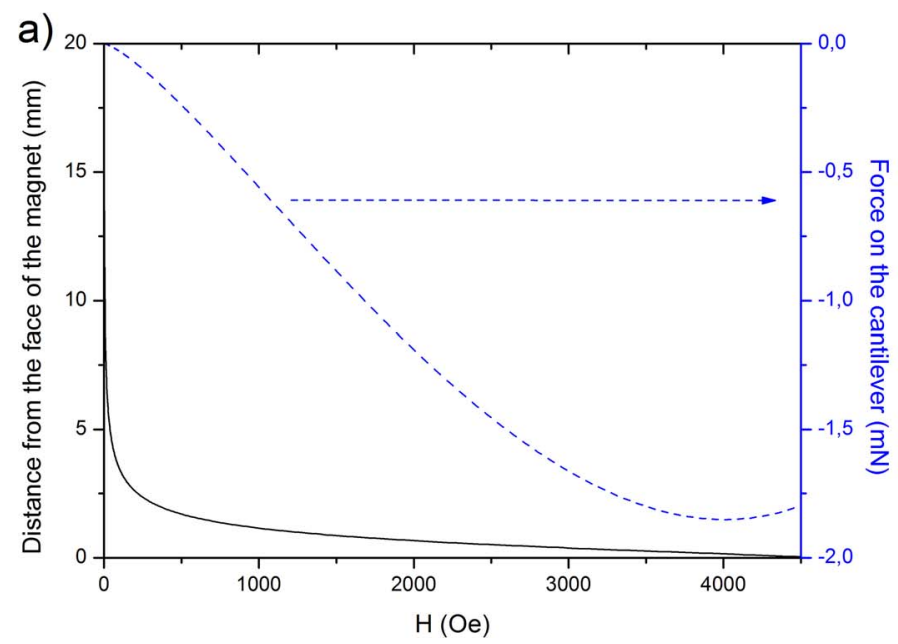

Figure 12. Force (blue, dashed line) acting on the cantilever tip as a function of magnetic flux and magnetic flux (black, continuous line) as a function of distance from the magnet face (a); comparison between calculated tip displacement and experimental data for permalloy coated cantilevers (b).

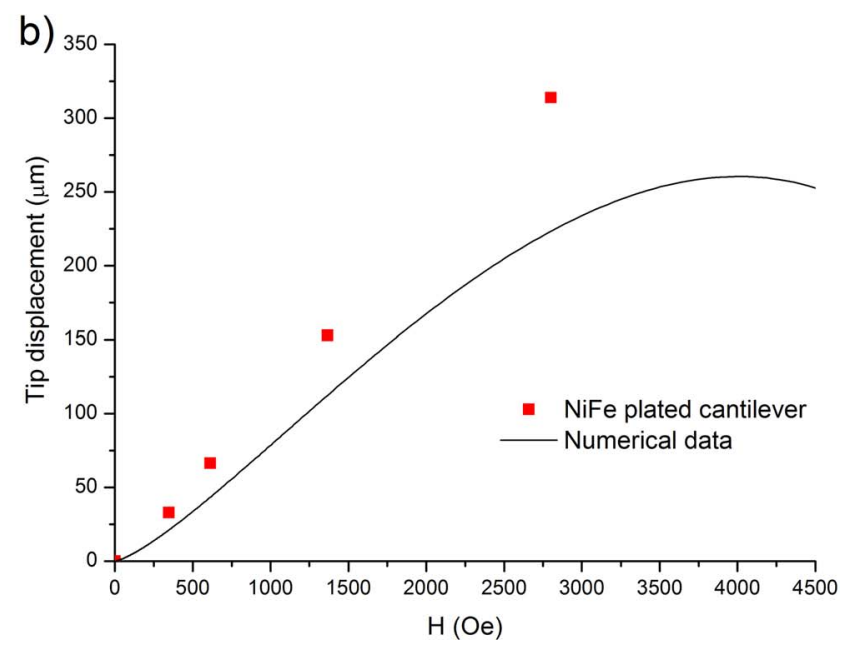

- modulus $\mathrm{E}_{\text {coat }}$ can be different, because $\mathrm{Cu}$ was deposited via electroless deposition and not by electrolytic plating like in Ref. 34

- modulus $\mathrm{E}_{\mathrm{res}}$ can vary according to $3 \mathrm{D}$ printing conditions and post-curing

- Equation 3 consider the case of a concentrated load applied at a distance $b$ from the base of the cantilever. The force applied to the permalloy layer is not however exactly a concentrated load, since it is applied on all the volume of the coating. For simplicity it was applied in the center of the plated length $(3 \mathrm{~mm} / 2=1.5 \mathrm{~mm}$ from the tip)

- the real section of the cantilever (as visible in Figure 10) is not a square, as expected from the design. This is due to the SLA printing process, that is not capable of achieving perfect square sections at the dimensional scale used to print the cantilevers

- Equation 2 is an approximation, and is valid only on the axis of the magnet. Zones of the cantilever that doesn't lie on the axis experience a different magnetic field, that is in general non-linearly dependent from the position

- the magnetic flux on the lower face of the cantilever can be significantly different from the flux on the upper face

Moreover, at high magnetic flux, the distance from the face of the magnet is considerably small. In these conditions, a minor decrement in the distance implies a great change in flux (Figure 12a). Equation 2 is not precise in the estimation of magnetic flux in close proximity of the face of the magnet, and for this reason the force (and consequently the displacement) calculated for $\mathrm{H}>3000$ Oe is not realistic (Figure 12a and 12b).

It is evident that a more accurate analysis of the actuation of the cantilever presented is possible only with the use of a FEM software. The presented model makes possible however to appreciate a pseudolinearity for the displacement values for $\mathrm{H}$ values below 3000 Oe. Also the relative order of magnitude of the displacements observed is confirmed by the modelling approach. Linear or pseudo-linear relationships between displacement and applied field have already been observed in the existing literature for structures not presenting a cantilever shape. ${ }^{22}$ Also in the case of existing magnetic actuator designs, linear relationships can be observed (if small displacements are considered). ${ }^{21}$

\section{Conclusions}

Electroless deposition of metals on stereolithography photocurable polymers was demonstrated. Uniform and adherent deposits were obtained on commercial and self formulated resins. Pretreatment exhibited a great influence on final adhesion, with untreated samples showing lack of adhesion. In particular selective dissolution of the 
resins by the alkaline environment was found to increase surface roughness and wettability. $\mathrm{Cu}$ and $\mathrm{NiP}$ were successfully deposited on the resins. The possibility to deposit further layers, both electroless or electrolytic, on the first electroless layer was demonstrated. Finally, the optimized electroless/electrolytic process was applied to the realization of prototypical cantilever shaped magnetic actuators. The devices obtained showed controllable actuation and a pseudo-linear behavior at low applied magnetic fields. As future development, FEM assisted design and further optimization may allow the production of realistic actuators. Such structures can be used as mechanical actuators for the functioning of other structures, for electrical switching or microfluidic control.

\section{References}

1. I. Gibson, D. W. Rosen, and B. Stucker, Additive Manufacturing Technologies, Springer, New York (2010).

2. D. T. Pham and S. S. Dimov, Rapid Manufacturing, Springer-Verlag, London (2001).

3. A third industrial revolution, The Economist, retrieved on 21st April 2012.

4. P. J. Bártolo (Ed.), Stereolithography: Materials, Processes and Applications, Springer, New York (2011).

5. M. Shellabear and O. Nyrhilä, DMLS - Development History and State of The Art, in LANE 2004 conference, Erlangen, Germany, Sept. 21-24 (2004).

6. R. Anitha, S. Arunachalam, and P. Radhakrishnana, J. Mat. Proc. Tech., 118, 385 (2001).

7. N. Fatkullin, T. Ikehara, H. Jinnai, S. Kawata, R. Kimmich, T. Nishi, Y. Nishikawa, and H.-B. Sun, NMR 3D Analysis Photopolymerization, Springer, New York (2004).

8. X. Zhang, X. N. Jiang, and C. Sun., Sensors and Actuators, 77, 149 (1999).

9. K. L. Mittal, Metallized Plastics Fundamental and Applied Aspects, VSP BV, Utrecht (2001).

10. J. J. Kuzmik, G. O. Mallory, and J. B. Hajdu, Electroless Plating: Fundamentals and Applications, The American Electroplaters and Surface Finishers Society, Orlando (1990).
11. S. Domenech, E. Lima, V. Drago, J. Lima, N. G. Borges, A. Avila, and V. Soldi, J. Appl. Surf. Sci., 220, 238 (2003).

12. A. Equbal and A. K. Sood, Coatings, 4574 (2014).

13. R. Bernasconi, G. Natale, M. Levi, and L. Magagnin, J. Electrochem. Soc., 163, D526 (2016).

14. A. Macor, E. de Rijk, S. Alberti, and T. Goodman, J-Ph. Ansermet, Rev. Sci. Instrum., 83, 046103 (2012).

15. B. Luan, M. Yeung, W. Wells, and X. Liu, Appl. Surf. Sci., 156, 26 (2000).

16. Pat. US7354870.

17. R. Lawes, MEMS Cost Analysis: From Laboratory to Industry, CRC Press, Boca Raton (2014).

18. L. F. V. Garcia, J. Microelectromec. Sys., 24, 2117 (2015).

19. S. Keller, D. Haefliger, and A. Boisen, J. Micromech. Microeng., 20, 045024 (2010).

20. Y. Zhang, H. H. Kim, B. H. Kwon, and J. S. Go, Sens. Act. B, 178, 47 (2013).

21. C. Liu, Mechatronics, 7, 613 (1998).

22. C. Y. Huang, T. R. Ger, M. F. Lai, W. Y. Chen, H. T. Huang, J. Y. Chen, P. J. Wang, and Z. H. Wei, J. Appl. Phys., 117, 17B740 (2015).

23. C. Credi, A. Fiorese, M. Tironi, R. Bernasconi, L. Magagnin, M. Levi, and S. Turri, Appl. Mater. Inter, 8, 26332 (2016).

24. H. Zhang, L. Shen, and J. Chang, J. Ind. Text., 41, 25 (2011).

25. L. Wang, L. Sun, and J. Li, Biores., 6, 3493 (2011).

26. H. E. M. Saleh, Polyester, chapter 4, InTech Open, Rijeka (2012)

27. R. Bernasconi, C. Credi, G. Natale, M. Tironi, F. Cuneo, M. Levi, and L. Magagnin, ECS Trans., 72, 9 (2016).

28. J. M. Camacho and V. Sosa, Rev. Mex. Fis., E59, 8 (2013).

29. Various authors, National Design Specification for Wood Construction, Design aid 6, American Forest and paper Association, Washington (2005).

30. W. Eberhardt, T. Gerhäußer, M. Giousouf, H. Kück, R. Mohr, and D. Warkentin, Sens. Actuators A, 97, 473 (2002)

31. http://www.amazingmagnets.com/magnetgrades.aspx, retrieved 22nd October 2016.

32. S. Cercelaru, A. M. Nguyen, P. Hesto, G. Tremblay, and J. C. Perron, J. Magn. Magn. Mater, 160, 338 (1996).

33. http://www.dwssystems.com/wp-content/uploads/documents/dl_260_x_technical_ datas.pdf, retrieved 22nd October 2016.

34. V. A. Lamb, C. E. Johnson, and D. R. Valentine, J. Electrochem. Soc., 117, 291C (1970). 